\title{
Undescended testis: What paediatricians need to know
}

John M Hutson ${ }^{1,2,3}$, Jaya Vikraman ${ }^{2,3}$, Ruili Li ${ }^{2}$, Joergen Thorup ${ }^{4,5}$

\footnotetext{
${ }^{1}$ Urology Department, The Royal Children's Hospital, Parkville, Victoria, Australia

${ }^{2}$ F Douglas Stephens Surgical Research Group, Murdoch Children's Research Group, Parkville, Victoria, Australia

${ }^{3}$ Department of Paediatrics, University of Melbourne, Victoria, Australia

${ }^{4}$ The Department of Pediatric Surgery, Righospitalet, Copenhagen, Denmark

${ }^{5}$ Faculty of Health and Medical Sciences, University of Copenhagen, Denmark
}

Address correspondence to: $\quad$ Prof John M Hutson AO

\author{
Chair of Paediatric Surgery \\ Urology Department \\ The Royal Children's Hospital \\ PARKVILLE, VICTORIA, AUSTRALIA \\ Phone: $\quad$ 62-3-9345 5805
}

This is the author manuscript accepted for publication and has undergone full peer review but has not been through the copyediting, typesetting, pagination and proofreading process, which may lead to differences between this version and the Version of Record. Please cite this article as doi: $10.1111 /$ jpc.13744

This article is protected by copyright. All rights reserved. 
Fax:

62-03-9345 7997

Email: john-hutson@rch.org.au

This article is protected by copyright. All rights reserved. 


\section{Introduction}

Testicular descent has evolved in most mammals to bring the intra-abdominal testis to the outside to enable it to reside in the subcutaneous scrotum at a lower temperature $\left(33^{\circ}\right)$ than the body core temperature of $37^{\circ} \mathrm{C}$. There are 2 steps in testicular descent, a transabdominal phase controlled by a new hormone, insulin like hormone-3 (INSL3), and an inguinoscrotal phase controlled by androgens [1]. The lower temperature of the scrotum is important for normal testicular physiology after birth, as maldescent leaves the testis in the abdomen, inguinal canal or groin at a higher temperature, leading to damage to the germ cells [2]. These germ cells become the stem cells for subsequent spermatogenesis, and are sensitive to the scrotal 'climate'. Undescended testis leads to damaging 'climate change' on the germ cells, and recent evidence suggests the detrimental effects begin around 3-6 months, when the neonatal germ cells transform into stem cells for spermatogenesis.

Clinical assessment of an infant with undescended testis (Figure 1) aims to determine whether the problem is congenital or develops later in childhood (see below) and to identify the location of the testis before surgical correction [3]. Hormone therapy rather than surgery has been found to be ineffective, and is not currently recommended [4-7]. 


\section{When do testes stop descending?}

In premature infants the testis may still be descending at the time of delivery, as the second or inguino-scrotal phase of testicular descent is normally complete by about 35 weeks' gestation. This makes incomplete descent very common in extremely premature infants but even at term there are still $3-4 \%$ of babies with undescended testis (UDT). In these babies about half of the testes will complete their descent by 12 weeks after term [8]. Beyond 3 months of age only a very small number of testes will descend further, so that 3 months of age is the optimal age to confirm the diagnosis of UDT and arrange surgical referral. Beyond 12 months of age descent of the testis without surgery is unlikely.

\section{Significance of the impalpable testis}

If the testis has failed to descend out of the inguinal canal it will be impalpable as the external oblique muscle forming the front wall of the inguinal canal (and covering the testis) makes even most canalicular testes impalpable (Table 1). All children with an impalpable testis need referral to a paediatric surgeon.

About $10 \%$ of UDT are impalpable in expert hands, implying a defect in the first or transabdominal phase of testicular descent, which is regulated by a newlydescribed testicular hormone, insulin-like hormone 3 (INSL3) $[9,10]$. INSL3 is an analogue of insulin and is produced by the Leydig cells. The first phase of testicular descent is rarely deranged, as INSL3 stimulates the genito-inguinal ligament, or gubernaculum, just to enlarge. This enlargement enables the swollen gubernaculum to hold the testis adjacent to the inguinal canal as the abdominal 
cavity of the fetus enlarges. As the first phase does not require the gubernaculum to move, failure of this process is much less common than failure of the inguinoscrotal phase, where the gubernaculum has to migrate $4-5 \mathrm{~cm}$ from the inguinal canal to the scrotum [11].

In many reports impalpable testis is more common than $10 \%$, as finding an UDT in the groin can be difficult, because the testis still resides inside the tunica vaginalis (the peritoneal membrane), the mesorchium. The location of the testis on a mesentery inside the tunica vaginalis makes it quite mobile, so it can be easily missed on physical examination if the examiner is looking for an UDT that is 'stuck' in the groin. (The trick to physical diagnosis is to be searching for a 'moving target').

It is also important to appreciate that sometimes the testis is impalpable because it is completely missing! This might be because it underwent prenatal torsion and ischaemic atrophy or even it is not a testis at all, but an abnormal gonad in a baby with a disorder of sex development (DSD). A useful clinical clue to previous prenatal torsion and atrophy is the size of the remaining, visible testis, which will undergo compensatory hypertrophy. This can be assessed on inspection of the scrotum by comparing the scrotal testis to the glans penis, which is roughly the same size. If the scrotal testis is visibly larger than the glans it suggests that there is only one testis. By contrast, if the testis is the same size as the glans it means there is very likely to be another testis that is in the canal or abdominal cavity, or just difficult to feel in the inguinal region because of the inguinal fat pad that is covering (and hiding) the testis or the baby will not keep still for the examination. 
A DSD can usually be easily excluded if the scrotum is fused normally and the penis is normal with no hypospadias, all of which show that prenatal androgen function was normal. By contrast, infants with a bifid or unfused scrotum \pm hypospadias as well as an impalpable gonad need immediate investigation for a DSD.

\section{How can you distinguish a retractile testis from true UDT?}

Normal retraction of the testis is controlled by contraction of the cremaster muscle, that regulates testicular temperature (optimum is $33^{\circ} \mathrm{C}$ ) and protects the testis from external trauma. The cremaster muscle is also sensitive to androgen levels, which are high at delivery and then at 2-6 months of age (called 'minipuberty'), but are lower after 6 months until the onset of puberty at 10-11 years of age. The high androgen levels at birth and during minipuberty make the cremaster more relaxed, and along with the effect of androgen on the dartos muscle in the scrotum (which causes the wrinkling of the scrotal skin) enable the neonatal testis to hang quite low in the pendulous scrotum. After minipuberty ends at about 6 months of age the cremaster and dartos muscles tighten up, making the scrotum quite small and often pulling the testis back out of the scrotum in what is known as retractile testis.

Normal retraction of the testis may be caused by the cremaster muscle pulling the testis up, which can be confirmed by the testis remaining low in the scrotum after it has been manipulated down into the scrotum during the physical examination.. Potentially abnormal retraction may also be caused by failure of the processus vaginalis (PV) (the peritoneal diverticulum inside of which the testis descends) to 
completely disappear after birth, leaving a fibrous remnant. As the scrotum grows away from the groin with enlargement of the pelvis the fibrous remnant of the PV prevents normal elongation of the testicular vessels and vas deferens, which leads to secondary 'ascent' of the testis. The fibrous PV often undergoes apoptosis and disappears in early childhood, so only about half of the 'retractile' testes seen at 1-2 years of age end up needing an operation, which is reserved for those that get worse with age.

We now regard 'retractile' testis as a 'grey zone' between normally descended and undescended testes. When the retractile testis gets worse with age, and once it can no longer reach the scrotum, we call it an ascending testis or acquired UDT, and recommend surgery. This is common in boys between 5 and 10 years of age, but can be seen already at the age of 3 years.

\section{Can testes 'ascend' with growth?}

The short answer is 'yes', although it is mostly apparent, as the testis may be actually stationary while the scrotum moves further from the groin as the pelvis enlarges during childhood. In neonates the distance from the external inguinal ring to the middle of the scrotum is about $4-5 \mathrm{~cm}$, but by 10 years of age it has increased to $8-10 \mathrm{~cm}$. This means that for the testis to remain in the scrotum during childhood the spermatic cord needs to double in length. When this fails, the testis seems to 'ascend' out of the scrotum when this is mostly an optical illusion caused by the testicular vessels failing to elongate in proportion to growth of the boy and the distance to the scrotum increases. Ascending testis is an alternate name for an acquired UDT. The cause in children with spastic diplegia in 
cerebral palsy is abnormal cremaster muscle spasm, but in normal boys the likely cause is thought to be persistence of a fibrous remnant of the PV which has not completely disappeared after birth.

'Ascending' testes usually need orchidopexy to prevent temperature-dependent degeneration of the germ cells occurring in later childhood. The optimal time for surgery is when the testis 'ascends' just out of the scrotum, which is usually in boys aged 5-10, with a peak incidence around 7-8 years. Ascending testes that are not treated by orchidopexy before 10 years of age sometimes descend spontaneously by 14-15 years of age with increasing pubertal androgens, but follow-up studies show that they have reduced fertility. It is still controversial in the European literature on whether early orchidopexy can overcome the risk of secondary infertility, but in the authors' opinion the preliminary evidence supports early surgery well before 10 years of age (and preferably by 4-5 years).

\section{What accounts for the testis that disappears after birth?}

The common cause of a 'vanishing testis', i.e. one that was seen in the scrotum at birth but later has disappeared, is that it has undergone ischaemic atrophy after perinatal torsion. Most of the time the testicular torsion has occurred before birth, and the visible gonad in the neonate is already dead, but complete involution takes a few months. Perinatal torsion is thought to occur just after testicular descent into the scrotum is complete, but before the tissues remodel and the testis becomes attached to the inside of the scrotum. 
Testicular atrophy triggers a compensatory growth stimulus to the remaining scrotal testis, which will enlarge. This can be determined by whether it is larger than the glans penis, which has roughly the same volume as a normal testis in small children. The prognosis for a boy with unilateral vanishing testis is excellent, as the remaining hypertrophic testis will be adequate for normal puberty and fertility.

\section{When is imaging indicated?}

For unilateral UDT imaging performed by the GP or paediatrician is usually unnecessary, as the UDT is frequently palpable when seen by the experienced surgeon. Imaging is reserved for when there is bilateral impalpable testes, as this can overlap with a DSD in a female with congenital adrenal hyperplasia with extreme virilisation (Prader 4-5) caused by excess androgens produced by the fetal adrenal gland. Paediatric surgeons rarely use imaging as they prefer diagnostic laparoscopy to identify the unilateral intra-abdominal testis, as endoscopy allows simultaneous surgical treatment in one or two stages.

\section{When should you suspect a disorder of sex development (DSD)?}

The 2 circumstances when a possible DSD needs to be considered are 1) when there is bilateral impalpable testes - you need to prove there are testes; and 2) when there is genital ambiguity as evidenced by 'hypospadias' + / 'bifid scrotum' here full DSD workup is required, as there are a number of DSD that present with this appearance.

Is there any role for hormone treatment? 
There is no current role for hormone treatment in UDT. Hormone therapy was based on the belief that androgens cause testicular descent and that UDT was caused by deficient androgen. This first started in the 1940's after the discovery of androgen, and has come and gone in fashion, as the scientific basis of testicular descent has been unravelled. Randomised, controlled trials have shown convincingly that hormone therapy with gonadotrophins and/or gonadotrophinreleasing factors are little better than placebo at causing testicular descent after birth [11]. This is probably because the causes of UDT are much more complex than single androgen deficiency. In addition, there is some evidence that the hormone therapy has detrimental effects on the testicular physiology and risks precocious puberty.

Although hormone therapy has been discredited as a treatment for testicular malposition, there is renewed interest in the possible benefits of hormone treatment to stimulate postnatal germ cell development in conjunction with orchidopexy. It was once thought that UDT was caused by deficiencies in the hypothalamic-pituitary-testicular axis (and hence the idea that gonadotrophins may help), but it is now recognised that abnormalities in the hypothalamicpituitary axis are likely in only about $20-30 \%$ of boys with UDT. In this small subgroup, hormone therapy may still have a place to stimulate germ cells and prevent infertility, and current research efforts are focussed on ways of identifying and defining the group, so that therapy is targeted appropriately. It may be that in future years some infants will receive medical treatment to prevent damage to their germ cell development as an adjunct to surgery. 


\section{What is the optimal age for orchidopexy, and why?}

As understanding of the physiology of the testis has advanced, the recommended age for orchidopexy for congenital UDT has fallen from 4-6 years in the 1970's to 612 months currently.

Timing of surgery is based on the premise that relocating the maldescended testis into the scrotum will either reverse or prevent abnormal germ cell development, and hence avoid later infertility and a higher risk of cancer. Recent research has shown that the crucial step in postnatal germ cell maturation that is deranged in UDT is transformation of the neonatal germ cell, the gonocyte, into a type-A spermatogonium, which is now recognised as the putative spermatogenic stem cell. This transformation occurs around 3-6 months, which is at the time of "minipuberty", when there is a transient burst of gonadotrophins and androgen. As some late-descending testes do reach the scrotum till up to 3 months of age and paediatric anaesthetists are anxious about possible effects of anaesthetic gases in infants, there is widespread consensus today that the optimal time for orchidopexy is between 6 and 12 months. After 1 year the prognosis for fertility looks to worsen, so it is important that referral mechanisms are in place for infants with UDT to be identified at 3 months, so orchidopexy can be arranged before 1 year of age.

For ascending, acquired UDT the optimal age for surgery remains controversial once the testis has ascended out of the scrotum, which is usually sometime between 5-8 years. There is accumulating evidence that early surgery at this time will improve the prognosis for fertility in these boys. It is thought that leaving the 
testis in the groin throughout later childhood will cause temperature-dependent loss of spermatogonial stem cells, which can be averted by surgery. In acquired UDT there seems to be a much lower risk of later malignancy, which is thought to be because during minipuberty at 3-6 months the testis was still in the scrotum and gonocyte transformation into stem cells was normal. By contrast, in congenital UDT, persisting gonocytes or undifferentiated spermatogonial stem cells that have not transformed into spermatogonia, but have not died, are thought to be the origin of the seminomas that occur in $20-40$ year old men who had cryptorchidism.

\section{What is the role of laparoscopy in impalpable testis?}

Laparoscopy has become the mainstay of surgical treatment of impalpable UDT, as it is the most reliable method of identifying the intra-abdominal anatomy, as well as enabling reliable orchidopexy. For testes within the inguinal canal or at the internal ring, laparoscopy enables adequate mobilisation of the vessels and vas deferens to allow placement of a scrotal testis in one stage. For testes higher in the abdomen, laparoscopy enables as 2-stage operation with the first stage consisting of ligation of the testicular vessels far enough away from the testis to enable increase of collateral blood supply via the artery to the vas and the cremasteric artery. In the second stage repeat laparoscopy facilities mobilisation of the testis on the enlarged collateral vessels. The 2-stage operation is known as the Fowler-Stephens operation, after Robert Fowler showed in the 1960's that the 3 arteries supplying the testis, the testicular artery, the artery to the vas and the cremasteric artery, form reliable anastomoses around the epididymis. This allows, 
in optimal cases, the testicular artery to be ligated without ischaemic injury to the testis. However, the overall success rate of this procedure is not more than $85 \%$.

This article is protected by copyright. All rights reserved. 


\section{References}

1. Hutson, J.M., J.M. Thorup, and S.W. Beasley, Descent of the Testis. 2 ed. 2016, Switzerland: Springer. 1-178.

2. Hutson, J.M., et al., Germ cell development in the postnatal testis: the key to prevent malignancy in cryptorchidism? Front Endocrinol (Lausanne), 2012. 3: p. 176.

3. Hutson, J.M. and J. Thorup, Evaluation and management of the infant with cryptorchidism. Curr Opin Pediatr, 2015. 27(4): p. 520-4.

4. Toppari, J., Paediatrics: New cryptorchidism guidelines reach a consensus. Nat Rev Urol, 2014. 11(8): p. 432-3.

5. Kolon, T.F., et al., Evaluation and treatment of cryptorchidism: AUA guideline. J Urol, 2014. 192(2): p. 337-45.

6. Pastuszak, A.W. and L.I. Lipshultz, AUA guideline on the diagnosis and treatment of cryptorchidism. J Urol, 2014. 192(2): p. 346-9.

7. Steinbrecher, H., The undescended testis: working towards a unified care pathway for 2014. Arch Dis Child, 2014. 99(5): p. 397-8.

8. Virtanen, H.E. and J. Toppari, Embryology and physiology of testicular development and descent. Pediatr Endocrinol Rev, 2014. 11 Suppl 2: p. 206-13.

9. Nef, S. and L.F. Parada, Cryptorchidism in mice mutant for Insl3. Nature Genetics, 1999. 22(3): p. 295-299.

10. Zimmermann, S., et al., Targeted disruption of the Insl3 gene causes bilateral cryptorchidism. Molecular Endocrinology, 1999. 13(5): p. 681-691.

11. Hutson, J.M., et al., The Regulation of Testicular Descent and the Effects of Cryptorchidism. Endocr Rev, 2013. 134(5): p. 725-52.

This article is protected by copyright. All rights reserved. 


\section{University Library}

\section{- M M I N E R VA A gateway to Melbourne's research publications}

Minerva Access is the Institutional Repository of The University of Melbourne

Author/s:

Hutson, JM;Vikraman, J;Li, R;Thorup, J

Title:

Undescended testis: What paediatricians need to know

Date:

2017-11-01

Citation:

Hutson, J. M., Vikraman, J., Li, R. \& Thorup, J. (2017). Undescended testis: What paediatricians need to know. JOURNAL OF PAEDIATRICS AND CHILD HEALTH, 53 (11), pp.1101-1104. https://doi.org/10.1111/jpc. 13744.

Persistent Link:

http://hdl.handle.net/11343/293803 